\title{
Degradation of Diclofenac under Irradiation of UV Lamp and Solar Light Using ZnO Photo Catalyst ${ }^{\dagger}$
}

\author{
Muhammad Tanveer ${ }^{1}$, Gokce Tezcanli ${ }^{2}$, Muhammad Tahseen Sadiq ${ }^{1, *}$, Syeda Memoona Kazmi ${ }^{1}$, \\ Nawal Noshad ${ }^{1}$, Ghulam Abbas ${ }^{1}$ and Asad Ali ${ }^{1}$
}

1 Department of Chemical Engineering, University of Gujrat Pakistan, Gujrat 50700, Punjab, Pakistan; Muhammad.tanveer@uog.edu.pk (M.T.); memoonakazmi712@gmail.com (S.M.K.); nawal.noshad.ict@gmail.com (N.N.); engr.ghulamabbas@uog.edu.pk (G.A.); asad.ali@uog.edu.pk (A.A.)

2 Tevfikpasask, Ozgul Apt, 21/8, Kalamıs, Istanbul 34726, Turkey; tanveer1524@gmail.com

* Correspondence: m.tahseensadiq@uog.edu.pk

+ Presented at the 1st International Conference on Energy, Power and Environment, Gujrat, Pakistan, 11-12 November 2021.

Citation: Tanveer, M.; Tezcanli, G.; Sadiq, M.T.; Kazmi, S.M.; Noshad, N.; Abbas, G.; Ali, A. Degradation of Diclofenac under Irradiation of UV Lamp and Solar Light Using $\mathrm{ZnO}$ Photo Catalyst. Eng. Proc. 2022, 12, 76. https://doi.org/10.3390/ engproc2021012076

Academic Editor: M. Salman Haider

Published: 6 January 2022

Publisher's Note: MDPI stays neutral with regard to jurisdictional claims in published maps and institutional affiliations.

Copyright: (c) 2022 by the authors. Licensee MDPI, Basel, Switzerland. This article is an open access article distributed under the terms and conditions of the Creative Commons Attribution (CC BY) license (https:/ / creativecommons.org/licenses/by/ $4.0 /)$.

\begin{abstract}
Diclofenac sodium (DCF) is a non-steroidal anti-inflammatory drug mainly used as an analgesic, arthritic and anti-rheumatic. This study deals with the degradation of diclofenac by photo catalytic-based advanced oxidation processes. Artificial UV lamp and solar rays have been applied to activate the $\mathrm{ZnO}$ catalyst, thereby generating highly oxidizing species. These species initiate the degradation process of the drug, which results in intermediates that finally dissociate into carbon dioxide and water. The solar reactor system is comprised of quartz and borosilicate tubes alternatively for the absorption and transmission of the solar rays to the pollutant sample. The degradation rate has been analyzed by composition analysis using high performance liquid chromatography. TOC and COD tests have also been conducted for degraded samples. ZnO catalyst loading was tested from $0.1 \mathrm{gm} / \mathrm{L}$ to $1 \mathrm{gm} / \mathrm{L}$ and the degradation rate showed a rising trend up to $0.250 \mathrm{gm} / \mathrm{L}$, but further increase in loading resulted in a drop in degradation. Similarly, degradation is higher in acidic condition as compared to neutral or basic $\mathrm{pH}$. The results showed a higher degradation rate for UV lamp irradiation as compared to the solar system. Moreover, TOC and COD reduction is also found to be higher for UV lamp photo catalysis.
\end{abstract}

Keywords: diclofenac; photocatalytic degradation; oxidizing species; catalyst loading; degradation

\section{Introduction}

Diclofenac sodium (DCF) is a frequently used drug and is prescribed as an analgesic, arthritic and anti-rheumatic drug and detected in fresh and wastewater at alarming levels [1]. Due to extensive human and veterinary cure, the number of NSAID annual prescriptions is around 80 million, making it almost $4.5 \%$ of all drugs prescriptions. The worldwide consumption of DCF provides a continuous release in aquatic environment from different sources, such as disposal from production sites, household discharge and its non-degraded and metabolized products after human and animal medical treatment [2]. In hospital wastewater, its concentration has been reported up to $8.5 \mu \mathrm{g} \mathrm{L}^{-1}$. The presence of diclofenac and its metabolic forms, even at very low concentrations, can cause cytotoxicity to marine lives, especially severe damage to liver, kidney and gill cells. Renal lesions problem associated with DCF is the major cause of massive decline $(95 \%)$ in vultures in Pakistan and India, making its existence critically rare in the subcontinent region. Moreover, its toxic effects have badly affected the vertebrates and fishes in aqueous environment [3]. Some studies have shown that the DCF traces in water bodies do not cause acute environmental toxicity; however, they have serious chronic effects and need to be addressed. DCF associated environmental and health issues have initiated the research for its complete removal or mineralization to harmless compounds. 
The aim of this study is to study the effect of different operating parameters, such as photo catalyst type, catalyst loading, and $\mathrm{pH}$ environment and radiation source. For this purpose, DCF degradation is studied under different loading concentrations of $\mathrm{ZnO}$ catalysts, employed under pure UV lamp $(254 \mathrm{~nm})$ and solar reactor irradiation consecutively. Effects of different $\mathrm{pH}$ environments on degradation is also examined.

\section{Methodology}

\subsection{Material and Reagents}

Diclofenac sodium salt was purchased from Sigma-Aldrich. Its solubility in water is $50 \mathrm{mg} / \mathrm{mL}$. Titanium (IV) oxide (anatase) and zinc oxide catalysts were also purchased from Sigma-Aldrich. ZnO catalyst is $99 \%$ pure with particle size $<100 \mathrm{~nm}$. Sodium hydroxide and sulfuric acid were purchased from Likit Kimya San Ve Tic A.S Kayisdag, Istanbul, and employed for the $\mathrm{pH}$ adjustment of the solution samples.

\subsection{Experimental Analyzing Techniques}

As amount of $1500 \mu \mathrm{M}$ stock solution of DCF was prepared by adding $47 \mathrm{mg}$ of diclofenac sodium in $100 \mathrm{~mL}$ water. Then, $30 \mu \mathrm{M}$ test samples were prepared by diluting $20 \mathrm{~mL}$ stock solution in $1 \mathrm{~L}$ deionized water. A lab scale UV reactor (Figure 1) was employed for artificial UV based experiment. DCF aqueous solution was introduced and recirculated on reactor via inlet and outlet ports. A UV Lamp (40 W, $254 \mathrm{~nm}$ ) was placed in quartz tube and immersed in the aqueous solution. Solar-based experiments were performed in a system comprised with absorber tubes (whether quartz or borosilicate) (Figure 2). Chrome plates were used as reflector for the rays harness the maximum intensity of solar light. The degradation rate of the diclofenac solution was analyzed by using high-performance liquid chromatography (HPLC) (Shimadzu Prominence LC-20A) having a Hypersil BDS C-18 column with Mediterranean Sea18 as packing material. Demineralization of the solution samples were analyzed by employing total oxygen demand (TOC) and chemical oxygen demand (COD) analyses.

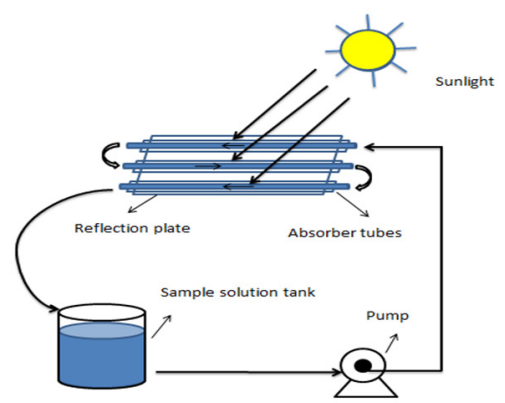

Figure 1. Lab scale UV reactor.

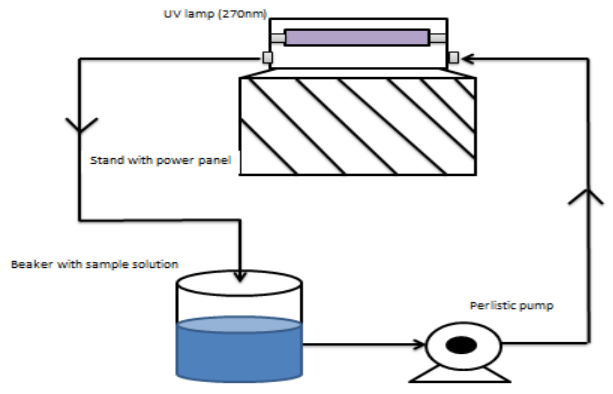

Figure 2. Solar reactor system for photo catalytic Experimentation. 


\section{Result and Discussion}

\subsection{Effect of Catalyst Loading of $\mathrm{ZnO}$}

In preliminary experiments, DCF degradation due to catalytic adsorption under dark conditions and photolysis (UV) was evaluated. The results showed no activation due to these factors. Then, photocatalytic degradation with $\mathrm{ZnO}$ concentration ranging from $0.10 \mathrm{~g} / \mathrm{L}$ to $1.0 \mathrm{~g} / \mathrm{L}$ was studied. The combined use of $\mathrm{UV}$ and $\mathrm{ZnO}$ loading gives significant DCF degradation. With increases in catalyst amount up to $0.25 \mathrm{~g} / \mathrm{L}$, the catalyst loading DCF degradation was promising, but further increases in loading led to drop in elimination process (Figure 3 ).

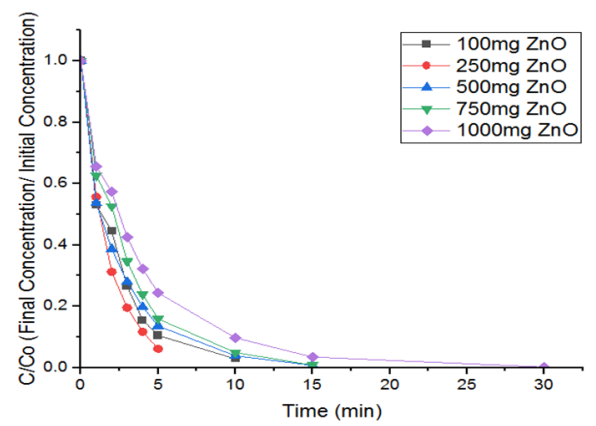

Figure 3. Effect of Catalyst Loading of $\mathrm{ZnO}$ on degradation rate.

It was found that increases in the catalyst loading supported the degradation process, but excessive amounts of catalyst can shield part of the photosensitive surface and consequently hinder or lag in degradation [4]. This threshold loading depends upon the reactor geometry, operating conditions, and initial substrate concentration. Studies show that $\mathrm{UV}$ irradiation on aqueous $\mathrm{ZnO}$ suspension with light energy greater than band gap energy of $\mathrm{ZnO}$ leads to the formation of conduction band electrons (e-) valance band holes $(\mathrm{h}+)$ [5]. With increasing catalyst loading, the rise in degradation can be associated with the enhanced availability of active sites on the $\mathrm{ZnO}$ surface and penetration of photo-activating light. After a certain loading level, the lowering of the degradation rate may be related to the enhanced light reflectance due to surplus $\mathrm{ZnO}$ particles and also increased opacity of the sample solution.

\subsection{Effect of $p H$}

The $\mathrm{pH}$ of the aqueous solution significantly affects the performance of photocatalytic degradation process. Conductance and valence band positions, size of aggregates formed by catalyst particles and surface charge density are based on $\mathrm{pH}$ conditions [6]. At first, the experimental solution was irradiated with $\mathrm{UV}$ at optimum $\mathrm{ZnO}$ loading $(0.25 \mathrm{gm} / \mathrm{L})$ under neutral $(\mathrm{pH}=7.7)$, acidic $(\mathrm{pH}=3)$ and basic $(\mathrm{pH}=11) \mathrm{pH}$ environments. Degradation results showed that under acidic $\mathrm{pH}$ conditions almost $95 \%$ of the pollutant is degraded within five mins, while for a basic or neutral environment the same percentage of degradation there doubled the time period. The catalyst performance further slowed down in the basic environment and took half an hour to mineralize the DCF sample (Figure 4).

As the Pka value of diclofenac is 4.15 [7] that indicate the DCF bears negative charge near neutral $\mathrm{pH}$, which results in electrostatic attraction pollutant and active sites of catalyst. This may increase the adsorption and degree of photo degradation of target micro pollutant. 


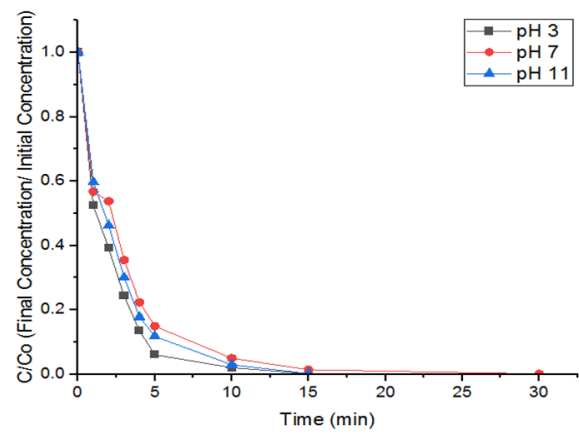

Figure 4. Effect of $\mathrm{pH}$ on degradation rate.

\subsection{Effect of Irradiation Source}

To initiate photo catalytic degradation process, the radiation source is considered the most important factor after solution $\mathrm{pH}$ and catalyst loading. Under UV lamp source, the optimum $\mathrm{pH}$ and catalyst loading was studied in previous section. To study the effect of solar irradiation, the borosilicate and quartz tubes were installed as ray absorbing materials. At optimum operating conditions, borosilicate tubes show better degradation results compared to quartz tubes (Figure 5). Moreover, mineralization study was also conducted by using TOC and COD analysis.

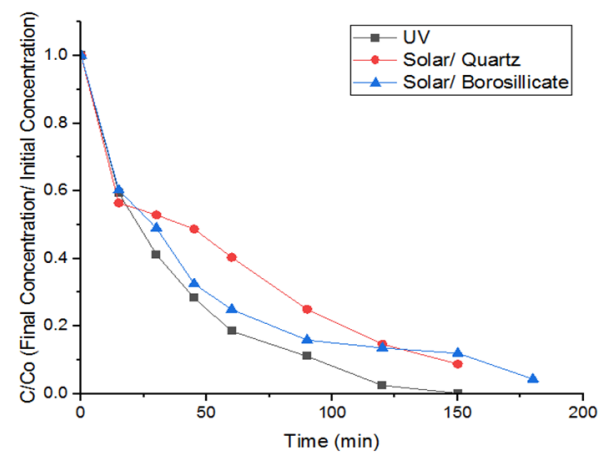

Figure 5. Effect of irradiation source (UV/Solar Quartz/ solar borosilicate) on degradation rate.

\section{Conclusions}

The degradation of DCF was investigated under UV and solar light using ZnO catalyst. The effect of catalyst loading was tested from $0.1 \mathrm{~g} / \mathrm{L}$ to $1.0 \mathrm{~g} / \mathrm{L}$ and found the optimum dosing conditions. Moreover, the role of $\mathrm{pH}$ was also analyzed employing acidic, neutral and basic working conditions. Along with degradation study, the mineralization of the degraded samples was also studied using TOC and COD analysis as shown in Table 1. The catalyst loading $0.25 \mathrm{~g} / \mathrm{L}$ was found optimum and the degradation process presents promising results under acidic conditions.

Table 1. Summary of diclofenac treatment by UV/ZnO and Solar/ZnO.

\begin{tabular}{cccc}
\hline Process & Degradation Rate $\left(\mathbf{m i n}^{-1}\right)$ & TOC Reduction & COD Reduction \\
\hline $\mathrm{UV} / \mathrm{ZnO}$ & 0.403 & $51 \%$ & $83 \%$ \\
Solar & 0.036 & $17 \%$ & $43 \%$ \\
(Borosilicate) $/ \mathrm{ZnO}$ & 0.015 & $15 \%$ & $47 \%$ \\
Solar (Quartz)/ZnO & & & \\
\hline
\end{tabular}

Conflicts of Interest: The authors declare no conflict of interest. 


\section{References}

1. Bai, X.; Wang, X.; Lu, X.; Liang, Y.; Li, J.; Wu, L.; Li, H.; Hao, Q.; Ni, B.J.; Wang, C. Surface defective g-C ${ }_{3} \mathrm{~N}_{4}{ }^{-x} \mathrm{Cl}_{\mathrm{X}}$ with unique spongy structure by polarization effect for enhanced photocatalytic removal of organic pollutants. J. Hazard. Mater. 2020, 398, 122897. [CrossRef] [PubMed]

2. Chen, X.; Li, N.; Zhu, R.; Li, S.; Yu, C.; Xia, W.; Xu, S.; Chen, X. Temperature-Program Assisted Synthesis of Novel Z-Scheme $\mathrm{CuBi}_{2} \mathrm{O}_{4}$ / beta- $\mathrm{Bi}_{2} \mathrm{O}_{3}$ Composite with Enhanced Visible Light Photocatalytic Performance. Nanomaterials 2018, 8, 579. [CrossRef] [PubMed]

3. Tanveer, M.; Guyer, G.T.; Abbas, G. Photocatalytic degradation of Ibuprofen in water using $\mathrm{TiO}_{2}$ and $\mathrm{ZnO}$ under artifical UV and solar irradiation. Water Environ. Res. 2019, 91, 822-829. [CrossRef] [PubMed]

4. Gao, L.; Zhou, B.; Wang, F.; Yuan, R.; Chen, H.; Han, X. Effect of dissolved organic matters and inorganic ions on TiO 2 photocatalysis of diclofenac: Mechanistic study and degradation pathways. Environ. Sci. Pollut. Res. Int. 2020, 27, $2044-2053$. [CrossRef] [PubMed]

5. He, J.; Yang, J.; Jiang, F.; Liu, P.; Zhu, M. Photo-assisted peroxymonosulfate activation via 2D/2D heterostructure of Ti ${ }_{3} \mathrm{C}_{2} / g-\mathrm{C}_{3} \mathrm{~N}_{4}$ for degradation of diclofenac. Chemosphere 2020, 258, 127339. [CrossRef] [PubMed]

6. Jang, J.; Shahzad, A.; Woo, S.H.; Lee, D.S. Magnetic $\mathrm{Ti}_{3} \mathrm{C}_{2} \mathrm{Tx}$ (Mxene) for diclofenac degradation via the ultraviolet/chlorine advanced oxidation process. Environ. Res. 2020, 182, 108990. [CrossRef] [PubMed]

7. Kovacic, M.; Katic, J.; Kusic, H.; Loncaric Bozic, A.; Metikos Hukovic, M. Elucidating the Photocatalytic Behavior of TiO ${ }_{2}-\mathrm{SnS}_{2}$ Composites Based on Their Energy Band Structure. Materials 2018, 11, 1041. [CrossRef] [PubMed] 